\title{
Husbandry and Herding: A Community-Based Approach to Addressing Illegal Wildlife Trade in Northern Botswana
}

\author{
Ben Heermans ${ }^{1 *}$, Jacques van Rooyen ${ }^{2,3+}$, Richard Fynn ${ }^{4 \dagger}$, Duan Biggs ${ }^{5,6,7 t}$, \\ Matthew Lewis ${ }^{3+}$ and John McNutt ${ }^{1}$ \\ 1 Wild Entrust, Maun, Botswana, ${ }^{2}$ Department of Veterinary Tropical Diseases, Faculty of Veterinary Sciences, University of \\ Pretoria, Pretoria, South Africa, ${ }^{3}$ Africa Field Division, Conservation International, Nairobi, Kenya, ${ }^{4}$ Okavango Research \\ Institute, University of Botswana, Maun, Botswana, ${ }^{5}$ Resilient Conservation, Centre for Planetary Health and Food Security, \\ School of Environment and Science, Griffith University, Nathan, QLD, Australia, ${ }^{6}$ Department of Conservation Ecology and \\ Entomology, Stellenbosch University, Matieland, South Africa, ${ }^{7}$ Centre for Complex Systems in Transition, School of Public \\ Leadership, Stellenbosch University, Stellenbosch, South Africa
}

\section{OPEN ACCESS}

Edited by:

Jenny Anne Glikman,

Instituto de Estudios Sociales

Avanzados (IESA), Spain

Reviewed by:

Annette Hübschle,

University of Cape Town, South Africa

Francis Masse,

Northumbria University,

United Kingdom

${ }^{*}$ Correspondence:

Ben Heermans

benheermans@gmail.com

tThese authors have contributed equally to this work

Specialty section:

This article was submitted to

Human-Wildlife Dynamics,

a section of the journal

Frontiers in Conservation Science

Received: 03 March 2021

Accepted: 13 August 2021

Published: 03 September 2021

Citation:

Heermans B, van Rooyen J, Fynn R,

Biggs D, Lewis $M$ and McNutt $J$ (2021) Husbandry and Herding: A

Community-Based Approach to Addressing Illegal Wildlife Trade in Northern Botswana.

Front. Conserv. Sci. 2:675493. doi: 10.3389/fcosc.2021.675493
Illegal bushmeat hunting is a major driver of wildlife population declines in Northern Botswana. Such declines raise concerns about the principles and integrity of the Kavango-Zambezi Transfrontier Conservation Area (KAZA) and regional economic stability which is heavily reliant on wildlife-based tourism. The KAZA landscape between Northern Botswana's protected areas consists of non-state land utilized communally by small agropastoralist communities. These communities are economically challenged by international beef trade policies, restricted access to grazing in nearby wildlife management areas and high conflict costs from living in close proximity to wildlife; some of the key factors identified as drivers of bushmeat hunting in the region. Here we describe how a model called Herding for Health $(\mathrm{H} 4 \mathrm{H})$ could address these drivers. We discuss strategies using a socio-economic centered Theory of Change (ToC) model to identify the role agropastoral communities can have in addressing illegal wildlife trade (IWT). The ToC conceptual framework was developed with input from a resource team consisting of scientific and implementation experts in $\mathrm{H} 4 \mathrm{H}$, wildlife conservation, illegal wildlife trade and livelihood development between September and December 2018, and with a validation workshop in March 2019 with government representatives from relevant ministries, NGO's, community-based organizations and private sector participants. We identify three pathways deriving from the ToC driven by community level actions to address IWT in the region. These include: increasing institutions for local enforcement, developing incentives for ecosystem stewardship and decreasing the costs of living alongside wildlife. The success of these pathways depends on underlying enabling actions: support for the development of institutional frameworks; building community capacity to facilitate informed best farming practices; and strengthening commitments to sustainable resource management to increase resilience to climatic and economic shocks.

Keywords: transfrontier conservation area, illegal wildlife trade, One Health, agropastoral, community-based conservation, human wildlife conflict, coexistence 


\section{INTRODUCTION}

The Okavango Delta (hereafter referred to as, the Delta) in northern Botswana is a key region for biodiversity conservation and economic development in Botswana and is currently facing immediate and long-term threats including oil and gas exploration, climate change and wildlife population declines resulting from illegal wildlife trade (IWT) [Burg, 2007; Magole and Magole, 2009; Rogan et al., 2015; Herding for Health (H4H), 2019; Richardson, 2021]. IWT is a major threat to global biodiversity conservation and sustainability with consequences that affect food security and development (Dickson, 2008; Phelps et al., 2016), as well as environmental, human and animal health [Gómez and Aguirre, 2008; United Nations Office on Drugs and Crime (UNODC), 2020]. As IWT occurs on various scales from subsistence use to organized international criminal syndicates, methods specific to the scale of illegal activities are needed to effectively counter this threat (Biggs et al., 2017).

Here we provide contextual and background information to outline key considerations to bushmeat drivers, communitybased conservation, and livelihood opportunities in the Delta region of the KAZA landscape before presenting the Herding for Health model. Finally, we present a process to which we adapt a general Theory of Change (ToC) model (Biggs et al., 2017; Skinner et al., 2018) to a community based approach to investigate the role agropastoral communities in wildlife rich Transfrontier Conservation Areas (TFCAs) can play in combatting illegal bushmeat hunting.

\section{Bushmeat Trade}

A 2011 aerial wildlife survey indicated significant declines in several ungulate species in the Delta (Chase, 2011). This raised alarm for Botswana's tourism industry and conservation sector, thus motivating an increase in wildlife monitoring around the Delta as well as an investigation of the underlying drivers of this decline (Rogan et al., 2015). The results of this surveybased study funded by the FAO indicated that illegal bushmeat hunting is pervasive in the Delta with an approximation of 2,000 hunters harvesting an annual take of $620,000 \mathrm{~kg}$ of mediumlarge herbivore biomass (Rogan et al., 2017). For some ungulate species, the study surmised that hunting offtake exceeds the intrinsic population growth rate, which would imply negative ecological and economic consequences. The negative effect of the bushmeat trade on ungulate populations has been observed across sub-Saharan Africa (Lindsey et al., 2013). Declines in herbivore populations will have cascading trophic effects on predator populations which are a major draw for photographic safaris (Rogan et al., 2017).

The extent and drivers of bushmeat hunting vary by context, from cases where it is primarily a subsistence activity to those where it is done on a larger scale for commercial gain (Duffy and St. John, 2013). In the Delta, bushmeat hunting is primarily an opportunistic pursuit of relatively wealthier households who use bushmeat as a form of supplementary income (Rogan et al., 2018). While exceptions in the Delta exist in the forms of syndicate organizations whose offtake exceeds $1000 \mathrm{Kg}$ p.a. and households that report subsistence usage, greater than half of hunters in the Delta reported an annual harvest of $<100 \mathrm{~kg} / \mathrm{yr}$ (Rogan et al., 2015). Three main drivers of bushmeat hunting identified in and around the Delta include: (1) economic opportunity, (2) lack of disincentives to hunt, and (3) negative attitudes toward wildlife (Rogan et al., 2015). Improved law enforcement and the development of alternative wildlife-based revenue streams that provide communities with conservation incentives are two recommended interventions to address illegal bushmeat hunting in the region (Rogan et al., 2018).

\section{Community-Based Conservation}

Within the Kavango-Zambezi (KAZA) landscape, 75\% of the land between state protected areas falls under traditional tenure systems (Cumming, 2011). Excluding WMAs, forest reserves and community concessions, $148,520 \mathrm{~km}^{2}$ of the remaining matrix is earmarked for agropastoral uses [Kavango Zambezi Transfrontier Area (KAZA), 2014]. In northern Botswana, the majority of rural communities attribute livestock as the main source of income generation, with some communities in western Ngamiland reporting livestock as supplying as much as $95 \%$ of household income [Darkoh and Mbaiwa, 2009; Habu Elephant Development Trust (HEDT), 2019]. In recognition of the need for integrated landscapes, initiatives promoting community based management systems for livestock-wildlife coexistence have been in development since the 1970s (Tyrell et al., 2017). Here we refer to coexistence as relating to both tolerance of conflict and co-occurrence, in recognition of the need to clarify from multiple interpretations that exist in literature (Nyhus, 2016; Frank and Glikman, 2019; Knox et al., 2021). Today, a number of livestock-wildlife coexistence projects in east and southern Africa demonstrate that conservation of large open landscapes and rural development can be achieved through the application of well-managed pastoral practices (Odadi et al., 2017; Tyrell et al., 2017; Keesing et al., 2018; Kiffner et al., 2020).

The Okavango Delta has been widely used by agropastoralists for centuries, which was documented by the first European expeditions to the area (Andersson, 1856; Livingstone, 1857). This practice continued until recent times (Basupi et al., 2017). However, at present, community access has largely been restricted for the purpose of economic growth leveraged by the global imperative for conservation, mostly to the benefit of government and outside international investors (Magole and Magole, 2009). Across Africa, communities have been displaced for the establishment of national parks, game reserves and wildlife management areas (Chatty and Colchester, 2002; West et al., 2006; Adams and Hutton, 2007). This type of "fortress" conservation strategy (Brockington, 2002; Berkes, 2004) was largely driven by the western concept of wilderness as a "pristine" untouched landscape and often involved the forced removal of resident human populations and reinforced a concept of division between people and nature (Adams and McShane, 1992).

Today, there is a growing awareness that the cooperation and participation of communities living in proximity to wildlife are critical to tackling IWT (Skinner et al., 2018). This is reflected in an increasing number of international policy recommendations that promote community based approaches (Biggs et al., 2017). Despite a wide range of trialed methods, standard protocols for 
community engagement are not widely accepted or regarded due to inadequate monitoring of the effectiveness of community based tactics and a disconnect between policy commitments and implementation (Cooney et al., 2016; Roe and Booker, 2019). Common methods that have evolved from decades of community initiatives involve; conservation awareness, development of nonwildlife based livelihoods, environmental stewardship incentives, increasing costs of participating in IWT and decreasing costs of living in proximity to wildlife (Roe and Booker, 2019). Despite a lapse in effective evaluation of such strategies, some key considerations that emerge in community engagement are: inclusivity and ownership in decision making and project design and implementation, effective governance and strengthened traditional institutions, net costs and benefits that influence community attitude either for or against conservation efforts and multilevel networks and enduring collaborations (Cooney et al., 2016, 2018; Armitage et al., 2019; Roe and Booker, 2019; Chan et al., 2020). Furthermore, communities are dynamic by nature and planning for successful outcomes requires understanding and sensitivity to local and social contexts (Cooney et al., 2018). For example, ethnic friction and cultural heterogeneity have been identified as challenges to community organization in Ngamiland, Botswana (Thakadu, 2005), which will have likely implications and require careful consideration for regional project design and implementation.

In Northern Botswana, community based tourism enterprises are common on the eastern, southern and northern periphery of the Delta, whereas the western side is characterized by traditional agriculture communities, underdeveloped tourism potential and greater human population density (Atkinson et al., 2019; Albertson, 2020). Veterinary cordon fences west of the Delta function primarily to prevent contact between clovenhoofed domestic livestock and Cape buffalo (Syncerus caffer) due to the risks of transmission of foot-and-mouth disease (FMD) (Atkinson et al., 2019). The fences effectually restrict market access for farmers living in Botswana's FMD control zones by prohibiting sales to the Botswana Meat Commission's higher priced international beef export industry and also separate these local communities from access to the resources in the wildlife management areas of the Delta (Atkinson et al., 2019). However, the network of over $10,000 \mathrm{~km}$ of fencing is porous due to frequent damage by elephants and high maintenance costs (Atkinson et al., 2019). Thus, veterinary cordon fences have been ineffective spatial barriers impacting both livestock and wildlife through exacerbating disease control efforts and human wildlife conflict (Ferguson and Hanks, 2010).

Together with opportunity and disease costs, human-wildlifeconflict (HWC) is another cost of conservation that is primarily shouldered by local communities and relates to tolerance to wildlife stewardship (Ceausu et al., 2020). Consequently, retaliation against wildlife responsible for $\mathrm{HWC}$ is common and leads to declines in wildlife populations regionally as well as globally (Woodroffe et al., 2005; Dickman, 2010). Killing of lions in retaliation for livestock losses has resulted in the removal of $30-50 \%$ of the lion population of the Delta's eastern panhandle (LeFlore et al., 2019). Lethal mitigation measures coupled with IWT, particularly in the form of illegal bushmeat harvest, pose a threat to sustainability of Botswana's wildlife populations and the region's tourism-based economy (Rogan et al., 2015).

Government and private anti-poaching units often lack understanding of the socio-ecological landscape, being mandated to operate at a regional scale, and are often easily evaded by locally-based poaching syndicates (Fynn and Kolawole, 2020). Furthermore, the para-militarization of conservation has drawn heavy criticism as a top-down approach associated with humanrights violations, enforcing exclusionary conservation practices on marginalized peoples, and deepening park-community divisions (Roe et al., 2015; Cooney et al., 2016; Massé et al., 2017). For these reasons, even proponents for militarized strategies to combat IWT, such as Botswana Defense Force's involvement in anti-poaching, advise caution with this intervention and that it should be strengthened by accountability and strategies to address local socio-economic inequalities (Cooney et al., 2018; Duffy et al., 2019). Despite extensive use of law enforcement as a method to address IWT (Roe and Booker, 2019), efforts to combat poaching have proven largely ineffective when communities have not been aligned with the conservation agenda (Fynn and Kolawole, 2020).

Conversely, through intimate regional, social, and ecological linkages, poaching is restricted when communities are on board with the conservation efforts, but all too pervasive when they are not (Scott, 1989; Fynn and Kolawole, 2020). Though communities at large are not the criminals in these cases, community sentiment can influence the prevalence of criminal activity. The unsuccessful attempts to obstruct poaching by government entities who lack the funding, manpower, local knowledge, and access to social networks represent a critical mismatch of scale (Cumming et al., 2006). At a local scale, communities are better equipped than centralized government through traditional knowledge, social networks, and human resources to effectively manage their natural resources (Murphree, 2004; Ostrom, 2009). Communities empowered with decision-making rights can gain significant conservation outcomes. Examples include: the increase in wildlife populations on Namibian Communal Conservancies (Muntifering, 2019), designation of new community conservancies adjacent to northern Kruger National Park (Fynn and Kolawole, 2020), and the decrease in elephant poaching reported in Kenya's Northern Rangeland Trusts (Northern Rangelands Trust, 2019) and in the WMAs of the Luangwa Valley (Lewis, 1990).

\section{Wildlife-Livestock Coexistence}

In light of the adverse consequences that arise from overlooking societal stressors to the communities adjacent to PAs, new conservation strategies that recognize, incorporate and promote both human and environmental complexities are urgently needed. This shortfall has been widely acknowledged (Ostrom, 2007) and has ultimately led to increasing complexity in conservation theory and new tools to guide the design of conservation strategy. PAs alone are inadequate to stem biodiversity loss because they are spatially-limited and consequently most biodiversity occurs outside PAs (Western et al., 2020). Thus, for large scale landscape conservation efforts (e.g., TFCAs) to be effective, the conservation scope has to widen 
beyond national parks and wildlife management areas to achieve habitat connectivity across the landscape (Mora and Sale, 2011). The notion of "working landscapes," that serve to conserve biodiversity while sustainably delivering the goods and services required by humanity aids to conceptualize how this connectivity within and between landscapes may be achieved (Miller et al., 2012; Kremen and Merenlender, 2018; Western et al., 2020). An environment for the successful raising and keeping of livestock is one such key service, especially considering that well-managed livestock can coexist with wildlife (Tyrell et al., 2017; Keesing et al., 2018; Kiffner et al., 2020).

Developing integrated livestock-wildlife systems in southern African communal rangelands will require addressing the key constraints that arise from market restrictions due to zoonotic and other economically important transboundary diseases (TADs), such as FMD control policies. Such restrictions pose major challenges to farmers (De Garine-Wichatitsky et al., 2013; Musoke et al., 2015; Van Rooyen, 2017) which can adversely affect community tolerance for wildlife and conservation efforts (Bedelian et al., 2007; Cumming et al., 2013; Van Rooyen, 2017). The severity of consequential market restrictions that animal disease policies inflict on rural farmers is exemplified by a 2007 FMD outbreak near Habu village in Northern Botswana that resulted in a 7-year closure of the beef industry in Ngamiland (Atkinson et al., 2019). Changes to the World Organization for Animal Health (OIE) policies that relate to FMD control measures now focus on disease prevalence in the beef commodity rather than the previously required geographical separation of livestock and wildlife, thus providing an opportunity for alternative risk mitigation measures (e.g., herding and kraaling) that help enable wildlife-livestock coexistence (Thomson et al., 2013). While some countries are slow to adopt these new OIE policies, Botswana is in a current state of policy reformation, and recently drafted new guidelines for FMD control with the aspiration of reaching previously restricted beef markets. Herding 4 Health $(\mathrm{H} 4 \mathrm{H})$ was conceptualized to aid farmers with market access through the development of alternative risk mitigation measures along the beef value chain, as well as to address related challenges on communal rangelands in southern Africa's TFCAs.

\section{Herding for Health}

Holistic approaches to address the challenges posed for conservation in complex systems have gained increasing focus in the 21st century (Du Toit et al., 2003; Smith and Maltby, 2003). Such approaches include interconnected goals of healthy, resilient communities, healthy animals (wild and domestic) and a healthy environment using the holistic, integrated principles of One Health in the framework of Health in Social-Ecological Systems (Zinsstag et al., 2011; Van Rooyen, 2017). The One Health Initiative started in 2007 as a strategy to promote collaboration and communication by health care practitioners across the whole spectrum of the field, including humans, animals and the environment and recognizes that the health of communities, livestock, wildlife, and ecosystems are interlinked [One Health Initiative (OHI), 2021]. The $\mathrm{H} 4 \mathrm{H}$ model was developed to address the complexity that One Health presents at the human-livestock-wildlife interface in Africa through methods that are simple yet practical, integrated and holistic, and acceptable to communities living with wildlife as well as policy makers, conservationists and development aid agencies (Van Rooyen, 2017). The $\mathrm{H} 4 \mathrm{H}$ model focusses on the health of rangelands, animals (wild and domestic), communities and governance [Peace Parks Foundation (PPF), 2018; University of Pretoria (UP), 2021] and aims to demonstrate how improved communication and collaboration across multidisciplinary fields from science, business, policy and development can come together to implement the shared goals of poverty alleviation, conservation, sustainable rangeland management and livestock production. $\mathrm{H} 4 \mathrm{H}$ became operational in 2017 as an implementation support program after drawing from 10 years of piloting and learning from partnerships in multiple sites in South Africa and elsewhere in southern Africa [Van Rooyen, 2017; Gaborone Declaration for Sustainability in Africa (GDSA), 2018; University of Pretoria (UP), 2021]. After the initial decade of piloting, additional $\mathrm{H} 4 \mathrm{H}$ projects have been initiated in Botswana, Mozambique, Zambia and Zimbabwe.

The methods endorsed by $\mathrm{H} 4 \mathrm{H}$ to address such issues as rangeland degradation and the use of herding and kraaling techniques promoted for human wildlife conflict mitigation stem from widely practiced and accepted strategies (Ogada, 2001; Odadi et al., 2017; Tyrell et al., 2017; Weise et al., 2018). Prerequisite community consultation and input on program design and project implementation is a fundamental component to the model and a critical ongoing process through engagement with targeted communities. $\mathrm{H} 4 \mathrm{H}$ uses voluntary contractual stewardship agreements based on the Conservation Agreements strategy of Conservation International (Niesten et al., 2010) as a compliance mechanism to ensure expectations and outcomes are met for all stakeholders. Conservation Agreements between communities and conservation NGOs or private enterprises work similarly to traditional institutions and communal agreements. Awards and penalties are built into the agreement to address issues that may arise, such as non-compliance (e.g., failure to curtail regional poaching may result in reduced livestock production support or pricing incentives at livestock auctions). The process is dependent on collaborative planning, designing, implementing and adjustment between target communities and partnering organizations. Conservation Agreements are currently implemented in over 20 countries globally to protect over 3 million hectares of critical biodiversity habitat [Conservation Stewards Program (CSP), 2021].

By adopting globally tested conservation approaches, such as incentive based methods to facilitate ecosystem stewardship, the initial pilot in South Africa has had success in facilitating increased market access and higher prices to farmers who apply practices of sustainable beef production on high biodiversity rangeland (Meat Naturally, 2019). Further recent gains through the extension services offered by $\mathrm{H} 4 \mathrm{H}$ include employment for communal herders, provision of vaccines, capacity building through training, support in establishing grazing plans, grazing committees, and other communal governance structures, and signing Conservation Agreements for over 240,000 hectares of communal land [Conservation South Africa (CSA), 2019]. 
The implementation of $\mathrm{H} 4 \mathrm{H}$ pilot programs in two villages characterized with large livestock numbers and high associated rates of HWC in Limpopo National Park, Mozambique, has resulted in favorable outcomes since project implementation commenced in February, 2020. Following deployment of mobile predator-proof bomas, no further incidences of livestock depredation or retaliatory killings have been observed in the pilot villages, whereas non-participating communities still experience high predation rates. In addition, park management has reported a marked improvement in relations with both communities participating in $\mathrm{H} 4 \mathrm{H}$ (P. Leitner pers. comm.).

The $\mathrm{H} 4 \mathrm{H}$ model seeks to reduce risk holistically and unlock diversified opportunities to harmonize the socioeconomic and ecological benefits of implementing better farming practices. Examples of socio-economic benefits include improved market access, better record keeping of cattle, lower rates of zoonotic disease transfer and fewer stock losses from theft and depredation. Examples of ecological benefits include: improved rangeland management and restoration, increased habitat connectivity through better stewardship of lands outside of protected areas, and a reduction in illegal wildlife trade through disincentive mechanizations and improved collaboration between government agencies. $\mathrm{H} 4 \mathrm{H}$ works through collaboration with NGOs, community-based organizations (CBOs) and other stakeholders with similar objectives and strong, long-lasting relations with communities on the ground. Such multi-level stakeholder networks are key to facilitating the success of community conservation initiatives (Berkes, 2007). H4H acts as a support system offering training, guidance in practical skill sets (e.g., veterinary care, rangeland management, human wildlife conflict mitigation, etc.) and strengthening natural resource governance capacity of participating communities [Southern Africa Wildlife College (SAWC), 2021].

The $\mathrm{H} 4 \mathrm{H}$ model is a valuable entry point for addressing IWT at local scales, as its foremost objective is to address the key concerns of agropastoral communities residing in or utilizing strategic wildlife habitat. $\mathrm{H} 4 \mathrm{H}$ aims to overcome the opportunity costs communities face by forgoing bushmeat as a source of protein through improving livestock production systems and promoting sustainable means for communities to benefit from wildlife (e.g., tourism), thus creating a pathway for wildlife-livestock coexistence. Building community resilience is a key objective of $\mathrm{H} 4 \mathrm{H}$, as the tourism industry is volatile, and livestock rearing is an important source of additional livelihood support (Lindsey et al., 2020). Recent livestock sales facilitated by $\mathrm{H} 4 \mathrm{H}$ partner Meat Naturally during COVID-19 lockdowns of 2020 demonstrate the value of livestock during periods of vulnerability (S. Frazee pers. comm.). Greater income stream diversity resulting from mixed livestock-wildlife systems (Keesing et al., 2018) further improves community resilience to global shocks. By reducing bushmeat poaching and consumption and promoting healthy livestock practices along the beef value chain, the $\mathrm{H} 4 \mathrm{H}$ model has the additional benefit of reducing risks for zoonotic disease emergence (Kock et al., 2009; Alexander et al., 2012).

$\mathrm{H} 4 \mathrm{H}$ recently developed a professional herder (also called ecoranger) training curriculum at the Southern African Wildlife
College (SAWC), a SADC accredited private educational facility in South Africa, which covers a range of natural resource management modules, including: primary animal health care, rangeland assessments, livestock production, HWC mitigation and livestock-wildlife contact mitigation, low stress animal handling and climate change adaptation strategies. The curriculum topics were developed after extensive consultation with livestock owners across $\mathrm{H} 4 \mathrm{H}$ sites on the skill sets most desired for professional herders. Through multi-stakeholder partnerships, $\mathrm{H} 4 \mathrm{H}$ sources financial assistance for students and ultimately aims to revitalize the age-old profession of herding practice through capacity building, promotion of gender equity and advancement of herders as trained professionals. Herding in the traditional form, where adolescents herded the household's herd, has been abandoned in many countries with compulsory schooling [Deutsche Gesellschaft für Internationale Zusammenarbeit (GIZ), 2019]. Herders within local communities are ideally positioned to improve regional security given that their work is field-based, they have detailed knowledge of the socio-ecological landscape and are mandated to look out for community interests. Capacitating herders with relevant skillsets and fostering tighter collaboration and communication with enforcement agencies increases security and the potential to address both stock theft and illegal wildlife offtake. Ideally, this would be the approach in communities where the value of wildlife and wildlife economies are treasured alongside other livelihood strategies such as agriculture and livestock production. In such a context, we developed a Theory of Change (ToC) to guide a novel community approach centered on husbandry to explore the potential to address illegal bushmeat hunting through the core community livelihood of livestock production.

\section{THEORY OF CHANGE APPROACH}

A Theory of Change is a framework for planning and evaluating initiatives that are designed to foster an anticipated social or environmental change (Vogel, 2012). The model is a derivation of logic planning models in social practice and has advanced to become a widely used tool in the international development and aid industries (Valters, 2014). This results chain approach has found relevance for conservation planners seeking to reevaluate and improve upon selected strategies (Biggs et al., 2017). The ToC is designed as a method to facilitate critical thinking in an adaptive and transparent process to ensure identified interventions lead to desired outcomes while accounting for assumptions made throughout the process.

In general, results chains are organized from actions to the consequential outputs and outcomes that achieve the overall impact. As several actions may be needed to achieve the desired impact, each action follows a linked pathway directed toward the desired outcome. Benchmarks are put in place to self-evaluate and monitor the effectiveness of each action in reaching its goals. ToC's are intended to guide an adaptive style of management that evolves over time through routine testing of the model's assumptions. Critical thinking processes that drive interventions for change 
are shown in ToC models as transparent and concrete strategies. This is not only beneficial for an organization's development, but for providing stakeholders and donors with a clear understanding of the complexities of change. For this reason, ToC's are becoming a mounting prerequisite for many donor organizations.

This ToC finds roots in the First Line of Defense (FLoD) framework structured for community-based conservation efforts developed in east Africa (Skinner et al., 2018). FLoD evolved into a ToC with a generalized approach to facilitate the engagement of communities in addressing IWT (Biggs et al., 2017). This generalized ToC was adapted to construct specific results chains for $\mathrm{H} 4 \mathrm{H}$ first through a series of email-based and in person discussions in 2017-2018 with a resource team consisting of scientific and implementation experts in $\mathrm{H} 4 \mathrm{H}$, wildlife conservation, illegal wildlife trade and livelihood development across multiple implementation sites in the SADC region. This preliminary input was used to structure the agenda for two workshops in Cape Town (25th-28th of September, 2018 and 3rd-5th of December, 2018), attended by the resource team to draft the ToC using the Open Standards framework [Conservation Measures Partnership (CMP), 2007]. A final stakeholder validation workshop was held in Maun (4th-6th of March, 2019) that included participants from government, NGO's, community-based organizations and the private sector. All participants to the Maun workshop participated voluntarily and with full disclosure as to the objectives and nature of the workshop to validate a conceptual framework. The resulting $\mathrm{H} 4 \mathrm{H}$ ToC identifies three pathways toward an overall objective of reducing pressure on wildlife populations in the Okavango from illegal bushmeat hunting through targeted interventions with agropastoral communities on the Delta periphery (Figure 1).

\section{Enabling Actions}

The underlying enabling actions are critical measures applicable to each pathway which serve to strengthen local governance through enhancing community capacity and providing support for institutions and institutional frameworks. Ultimately, strengthened governance will facilitate compliance with the Conservation Agreement mechanism which underpins the model. Community capacity building is an essential and ongoing process in the $\mathrm{H} 4 \mathrm{H}$ model which is reflected in curriculum development, and skill enhancement through training. Strengthening of the Conservation Agreement mechanism entails a highly collaborative process reached through consultative meetings with target communities to ensure expectations are agreed upon through adaptive management. $\mathrm{H} 4 \mathrm{H}$ support for development and implementation of legal institutional frameworks (e.g., the establishment of grazing committees) speaks to strengthening local governance to ensure equitable benefit sharing, accountability and ultimately improved resource management.

\section{Pathways}

Actions aimed at making it more difficult and costly to participate in IWT (Pathway A) are widely recognized and practiced wildlife crime reduction strategies (Challender and MacMillan, 2014). Botswana's Department of Wildlife and National Parks (DWNP) sub-district offices and the Botswana Defense Force are limited in resources and personnel to curb the onslaught of IWT in Botswana (Rogan et al., 2015). While private antipoaching units have been effective in some of the WMAs of the Delta, their funding is finite, coverage is limited and mandate restricted in their areas of operation. Pathway A focusses on solidifying collaboration between local enforcement entities (e.g., community scouts, herders and farmers) through training and information sharing while also strengthening decision making rights, traditional institutions, cultural practices and social norms to wildlife utilization. Elevating the social stigma of poaching will ultimately require increasing the perceived worth of wildlife which can be realized through incentivizing mechanisms for wildlife and ecosystem stewardship (Pathway B).

Pathway B aims to motivate individuals and the community at large to take stronger action against IWT through livestockbased (Sub-pathway B1) and non-livestock based (Sub-pathway B2) incentive-based approaches to ecosystem stewardship. Sub-pathway B1 focusses on improving livestock production and market constraints to foster a pro-conservation livestock economy. Pathway B is founded on the principles of decisionmaking rights over, and benefits from natural resources through local community institutions, developed through decades of global research on the factors that enable robust institutions (Murphree, 2009; Ostrom, 2009). These actions include training and strengthening community capacity for livestock management (community institutions) and securing sustainable market access through mechanisms that encourage wildlife friendly practices. The results include better economic returns from livestock linked to good conservation practices.

In the Delta, the tourism industry represents a vast untapped market for communal farmers, with large potential for creating incentives derived from conscious consumers who are willing to pay higher prices for goods and services that support community conservation initiatives through wildlife friendly branding schemes. While the model's preliminary aim is to establish consistent uninterrupted market access, $\mathrm{H} 4 \mathrm{H}$ has successfully trialed facilitating higher value markets for communal farmers in Mnisi, South Africa, where the target consumers are safari lodge clientele of Kruger National Park (M. Grover pers. comm.). Through collaboration with private enterprise, farmers are awarded higher market prices linked to conservation actions such as planned grazing and other rangeland restoration techniques. This serves to highlight to farmers that wildlife can have benefits in indirect ways. The key emphasis is on linking to the robust principles of decision-making rights and benefits known to promote conservation objectives by local communities (Murphree, 2009; Ostrom, 2009; Persha et al., 2011).

Sub-pathway B2 focusses on developing non-livestock based incentives for wildlife stewardship through both the financial and non-financial rewards for protecting and sustainably managing wildlife and their habitats. Actions on this pathway include those focused on the development of activities like tourism, employment for communal herding linked to conservation, carbon offsets, etc., that generate benefits from wildlife 


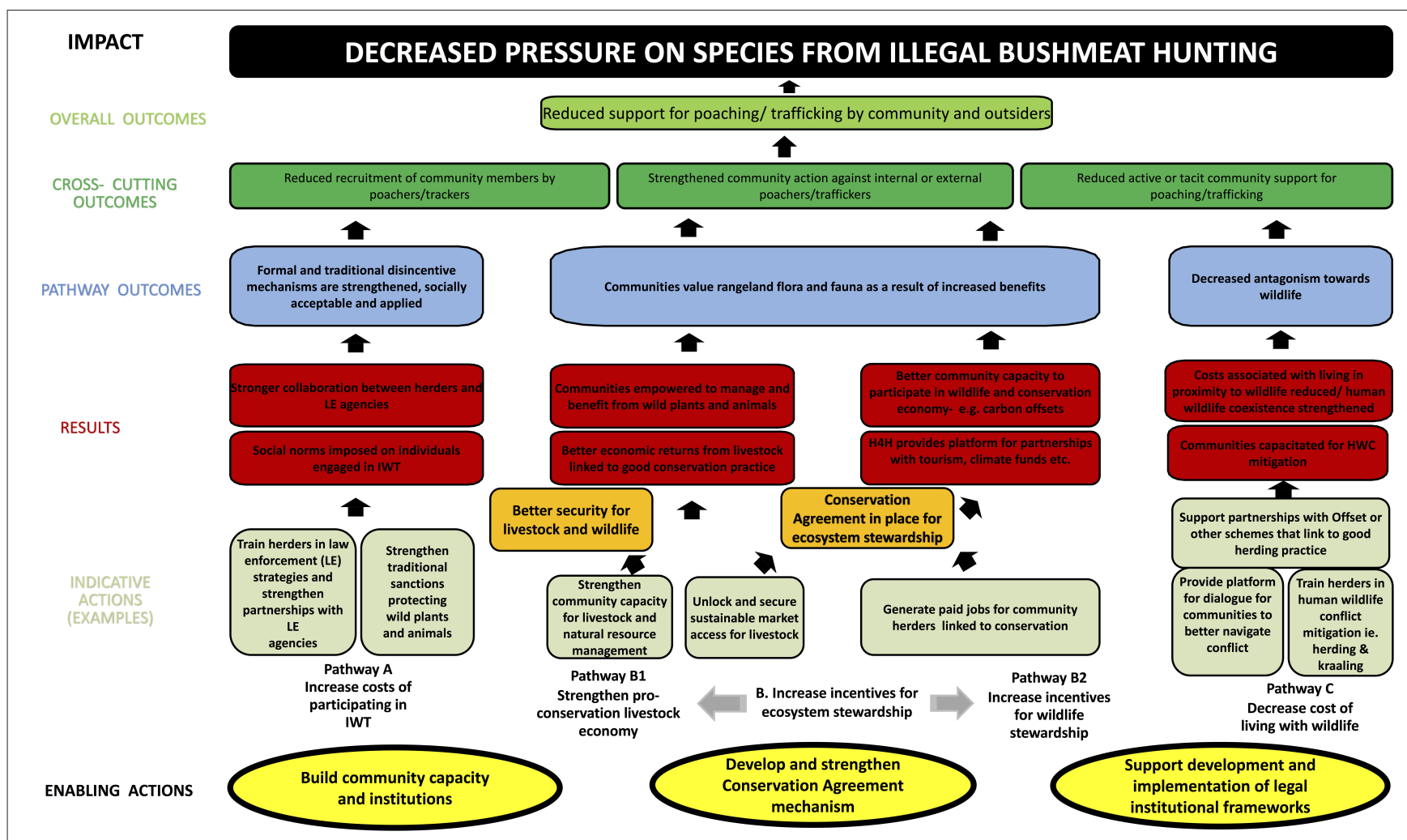

FIGURE 1 | Theory of Change (ToC) developed for the Herding 4 Health $(\mathrm{H} 4 \mathrm{H})$ model to identify the role agropastoral communities can play in addressing illegal wildlife trade. The ToC was developed from a series of stakeholder workshops between September and December 2018. A ToC validation workshop was held in March 2019 in Maun, Botswana which included government representatives from relevant ministries, NGO's, community-based organizations and private sector participants.

conservation and build capacity in individuals and communities to participate and benefit from these initiatives. Communities are then better able to benefit from the wildlife and conservation economy through a range of mechanisms that may include professional herder and ecoranger training and employment, tourism development and carbon offset payments through improved rangeland management. In addition, $\mathrm{H} 4 \mathrm{H}$ provides an institutional platform for the development of partnerships with communities to access climate funds, tourism enterprises and training centers. The incentive-based approaches of Pathway B are contingent on compliance with the Conservation Agreement mechanism whereby penalties to wildlife crime activities are applied by withholding incentives. Conservation Agreements can also serve to facilitate benefit sharing between communities and private enterprise. For example, tourism enterprises may opt to buy local produce and support the salaries of professional herders due to a reduction in numbers of stray cattle in wildlife concessions, reduced retaliatory killings due to HWC and the opportunity to market social and environmental support to conscious consumers.

Finally, Pathway $\mathrm{C}$ focuses on reducing the costs to individuals and communities living with wildlife, in particular through improved HWC mitigation. Actions in this pathway aim at increasing the capacity of herders to effectively mitigate conflict, using techniques such as herding and protecting livestock in specially designed predator-proof boma enclosures during the night (kraaling). Successfully mitigating conflict helps reduce the cost of living alongside wildlife and helps de-escalate the conflict, which allows for dialogue with communities to explore the complex challenges of HWC. The socialecological framework for ecosystem disservices and services (SEEDS) provides a concept for addressing HWC where the disservices (costs) of wildlife on local communities may strongly outweigh the services. For example, situations where tourism companies, national governments and the international conservation community mainly benefit from the services while experiencing little of the disservices (Ceausu et al., 2020). Pathway C explicitly aims to correct the skewed ratio of wildlife disservices to services for local communities by creating more equitable and sustainable conservation outcomes.

There are various feedback loops between the pathways. For example, success with the law enforcement strategy in Pathway A may lead to increased human wildlife conflict as predator numbers increase, which would instigate more consideration to the mitigation activities in Pathway C. Similarly, if the success of improved husbandry in Sub-pathway B1 leads to increased herd sizes, it could consequently result in increased rangeland degradation. This scenario would require a Conservation Agreement that mitigates rangeland degradation through community-driven regulation of herd size in accordance 
with proper rangeland management practices. In this regard, the $\mathrm{ToC}$ is to be taken as an adaptive decision support tool for conservation practitioners in partnership with local communities and relevant stakeholders which will require continuous reassessment, development and negotiation as it is implemented.

\section{Key Assumptions}

The communities where $\mathrm{H} 4 \mathrm{H}$ is implemented are often subject to fast-changing external pressures and they, along with the individuals who comprise them, vary in socio-economic, cultural and political factors. As such, the guiding pathways developed in this ToC need to be contextually assessed before implementation. Aside from the prerequisite enabling actions identified in this ToC, governance challenges from the local to international scale including transparency, corruption, elite capture, decentralization of natural resource rights, zoonotic disease and other biosafety control policies and legislation regarding wildlife crime (Frost and Bond, 2008; Thomson and Penrith, 2011; Rogan et al., 2015; Biggs et al., 2017) are critical factors for consideration in the attempt to address IWT in agropastoral communities.

$\mathrm{H} 4 \mathrm{H}$ relies heavily on community confidence in the assumption that herders charged with custody of a common property (livestock) are responsible and acting on a communitys' best interests. The link herders can provide between livestock and wildlife security is based on the assumption that they themselves will not be lured into illicit behavior. Thus, key assumptions for a strategy that relies upon herders to assist in wildlife related law enforcement activities include: (1) Communities value wildlife and strive to benefit from its presence (2) Communities recognize that there is a poaching problem, and (3) Communities are willing to allow herders to collect data and report on illegal activity. There is empirical evidence to show that local communities are more likely to invest time and energy into forming local institutions for developing and enforcing rules about conserving natural resources if, (1) They have ownership and decision-making rights over those resources, and (2) The costs of conserving those resources are strongly outweighed by the benefits (Lewis, 1990; Ostrom and Nagendra, 2006; Murphree, 2009; Ostrom, 2009; Persha et al., 2011; Lotter and Clark, 2014; Muntifering, 2019). When bestowed with the responsibility for making rules about wildlife conservation and community game guards are used for monitoring and enforcing these rules, local communities once notorious for poaching can become ardent conservationists (Lewis, 1990; Lotter and Clark, 2014; Muntifering, 2019). These are key and non-substitutable principles for the ToC.

Community members engaged as game guards or related roles may face open hostility, risks to personal safety and a breakdown of social cohesion within the community by members involved in wildlife crime (Painter and Wilkie, 2015). In this respect, the balance of support within the community needs to be weighed so that herders do not face excessive intimidation by those involved in illegal offtake. The level to which communities and external law enforcement are willing to collaborate, and the degree to which these strengthened relations lead to tighter action against, rather than collusion with, wildlife crime will be a paramount consideration in this decision.

In the Habu community, an $\mathrm{H} 4 \mathrm{H}$ pilot project site in the western Delta, community scouts employed by a local CBO, the Habu Elephant Development Trust, have the dual duties of wildlife monitoring and aggregate herding. While only in its third year of implementation, preliminary results have discovered linkages in criminal activity associated with stock theft and illegal bushmeat harvest which has demonstrated the critical role herders/scouts can play in reporting and acting on wildlife crime through tight associations with local law enforcement and the backing of community leadership. The Habu project was initiated with international donor support and aims to work toward sustainability through revenue generated from improved market access, livestock management and tourism levees. The dual role of skilled herders in security and livestock management has presented a few challenges, however. The pilot has been subject to the common complications of community policing, such as under-reporting of illegal activities and minor harassment. However, through continued community outreach and education, the community scouts of Habu have gained traction in garnering community support and have reduced illegal activity in a community identified conservation zone [Habu Elephant Development Trust (HEDT), 2019].

To dissuade community members from engaging in wildlife crime, the alternatives must be equally lucrative and appealing (Keane et al., 2008). Major assumptions for strengthening ecosystem stewardship incentives are: (1) That the target communities are on board with the $\mathrm{H} 4 \mathrm{H}$ program, (2) That communities are willing to acquire new skill sets, (3) That the activities of improved livestock management and rangeland restoration can demonstrate positive outputs that are comparable to illicit means of livelihood enhancement, (4) That better farming practices will result in increased benefits for the farmers, and (5) That the community awareness of the $\mathrm{H} 4 \mathrm{H}$ protocol or approach instills acceptance of a wildlife-livestock coexistence strategy.

Assumptions related to decreasing the cost of living with wildlife are: (1) That communities are willing to engage in $\mathrm{H} 4 \mathrm{H}$ activities, and (2) That the wildlife-livestock risk and conflict mitigation activities are effective. While the effectiveness of professional herding and kraaling and the willingness of a community to take on these activities have been tested and realized in several of the $\mathrm{H} 4 \mathrm{H}$ sites as well as elsewhere, increased HWC mitigation measures may not always lead to increased tolerance of wildlife (Dickman, 2010). Some conservation activities may result in unintended consequences. For example, a compensation scheme that is not linked to a system that enables participation in a program such as $\mathrm{H} 4 \mathrm{H}$ as a prerequisite for compensation for livestock loss can disincentivize best practice adoption or even result in false reporting which in turn fosters greater resentment against carnivores.

Successful HWC mitigation measures alone will not be enough to keep farmers in the $\mathrm{H} 4 \mathrm{H}$ program. Thus, economic benefits to herding, especially successful implementation of wildlife friendly beef production practices and in the long term, improved rangeland, cattle production and enhanced alternative 
livelihood opportunities are critical components to the model. The strength of the $\mathrm{H} 4 \mathrm{H}$ model is that with the same activities it addresses both risk mitigation and unlocked opportunities through collective action and negotiated agreements that are context specific. Similarly, $\mathrm{H} 4 \mathrm{H}$ can provide a platform to negotiate access and benefit sharing frameworks between protected areas and communities in a win-win, ecological and biodiversity sound way which would provide major incentives for wildlife stewardship. $\mathrm{H} 4 \mathrm{H}$ plays a key role in providing greater resilience to community-based conservation by integrating conservation with livelihoods and co-existence of livestock with wildlife by providing a way of sustainably integrating livestock with wildlife (livelihood diversification) (Fynn et al., 2016). This can take conservation strategy into a new multi-dimensional era beyond the one-dimensional tourism income approach that renders conservation vulnerable to global shocks that jeopardize tourism income, while also improving local community attitudes to conservation by increasing benefits to local communities of enhanced access to resources and participation in management of wildlife.

\section{CONCLUSIONS}

The issues surrounding IWT are dynamic and complex (Challender et al., 2015) and require targeted interventions at multiple scales. Failure to attract or solicit community support has resulted in the underperformance of many conservation efforts in achieving their intended outcomes (Ban et al., 2013). Indirectly related to this are equally complex issues surrounding HWC which affect community sentiments toward wildlife and pending on context can influence whether human-wildlife interactions are viewed as conflict or coexistence (Frank and Glikman, 2019). Also of critical concern are prevailing power dynamics and where decision-making rights and the authority to manage conflict lie (Massé, 2016) which will also influence tolerance toward conservation. The holistic, integrated approach of $\mathrm{H} 4 \mathrm{H}$ aims to address several of the contributing factors of illegal bushmeat hunting at a community level and should be considered as a component to the broader strategy to combat IWT (Biggs et al., 2015, 2017). Furthermore, in times of severe stress, rural people increasingly turn to the exploitation of nature, as observed in recent spikes of bushmeat harvest reported in Uganda and Kenya as well as the spike in the poaching of endangered green turtles in Madagascar in the past year due to effects of COVID19 lockdowns (Mupatsi, 2020). The $\mathrm{H} 4 \mathrm{H}$ model aims to build resilient communities based on livelihood diversification that can withstand stressors like global pandemics,

\section{REFERENCES}

Adams, J. S., and McShane, T. O. (1992). The Myth of Wild Africa: Conservation Without Illusion. Berkeley, CA: University of California Press.

Adams, W. M., and Hutton, J. (2007). People, parks and poverty: political ecology and biodiversity conservation. Conserv. Soc. 5, 147-183. Available online at: https://ecoinsee.org/lib_docs/Political_Ecology_and_Biodiversity_ Conservation.pdf (accessed August 19, 2021). tourism declines, recessions, or climate-related disasters, while also reducing HWC. If global-level stressors continue to increase in severity, the resulting increase of IWT will be large.

While this ToC was drawn from the experience of multiple authorities and stakeholders, many of the assumptions still need empirical validation. A common limitation to some ToCs is that they are based on "weak and selective" evidence which can bolster misled confidence in a resolution without complete comprehension of the problem at hand (Valters, 2014). Thus, this ToC should be considered as an adaptive mechanism, the progression of which will require co-learning and co-management from other $\mathrm{H} 4 \mathrm{H}$ sites, locally specific implementation in a nuanced style, targeted and applied monitoring and evaluation, and a realistic approach that accounts for the importance of different stakeholder perceptions and considers the importance of processes and relationships in achieving outcomes. Ultimately, we aim to demonstrate the use of this model, whose assumptions will be tested through monitoring, open dialogue, collaboration, and feedback with partnering communities, to strengthen the role $\mathrm{H} 4 \mathrm{H}$ can play in community driven wildlife crime prevention.

\section{DATA AVAILABILITY STATEMENT}

The original contributions presented in the study are included in the article/supplementary material, further inquiries can be directed to the corresponding author.

\section{ETHICS STATEMENT}

The studies involving human participants were reviewed and approved by University of Pretoria Research Ethics Committee. Written informed consent for participation was not required for this study in accordance with the national legislation and the institutional requirements.

\section{AUTHOR CONTRIBUTIONS}

All authors listed have made a substantial, direct and intellectual contribution to the work, and approved it for publication.

\section{ACKNOWLEDGMENTS}

We thank the participants of the Maun Herding for Health and Community-driven Wildlife Crime Prevention workshop which was funded jointly by Conservation International, Conservation South Africa, Meat Naturally and Peace Parks Foundation. 
Armitage, D., Mbatha, P., Muhl, E., Rice, W., and Sowman, M. (2019). Governance principles for community-centered conservation in the post 2020 global biodiversity framework. Conserv. Sci. Pract. 2:e160. doi: 10.1111/ $\operatorname{csp} 2.160$

Atkinson, S. J., Bing, M., McNutt, J. W., Marshall, C., Masedi, M., Osofsky, S. A., et al. (2019). Gap Analysis on the Implementation of Commodity-Based Trade of Beef in Ngamiland, Botswana. Report prepared in consultation with the Government of Botswana's Department of Veterinary Services. AHEAD programme, Cornell University.

Ban, N. C., Mills, M., Tam, J., Hicks, C., Klain, S., Stoeckl, N., et al. (2013). Towards a social-ecological approach for conservation planning: embedding social considerations. Front. Ecol. Environ. 11, 194-202. doi: 10.1890/110205

Basupi, L. V., Quinn, C. H., and Dougill, A. J. (2017). Using participatory mapping and a participatory geographic information system in pastoral land use investigation: impacts of rangeland policy in Botswana. Land Use Policy 64, 363-373. doi: 10.1016/j.landusepol.2017.03.007

Bedelian, C., Nkedianye, D., and Herrero, M. (2007). Maasai perception of the impact and incidence of malignant catarral fever (MCF) in southern Africa. Prevent. Vet. Med. 78, 296-316. doi: 10.1016/j.prevetmed.2006.10.012

Berkes, F. (2004). Rethinking community-based conservation. Conserv. Biol. 18, 621-630. doi: 10.1111/j.1523-1739.2004.00077.x

Berkes, F. (2007). Community-based conservation in a globalized world. Proc. Natl. Acad. Sci. U.S.A. 104, 15188-15193. doi: 10.1073/pnas.0702098104

Biggs, D., Cooney, R., Roe, D., Dublin, H., Allan, J., Challender, D. W. S., et al. (2015). Engaging Local Communities in Tackling Illegal Wildlife Trade: Can a 'Theory of Change' Help? London: International Institute for Environment and Development.

Biggs, D., Cooney, R., Roe, D., Dublin, H., Allan, J., Challender, D. W. S., et al. (2017). Developing a theory of change for a community-based response to illegal wildlife trade. Conserv. Biol. 31, 5-12. doi: 10.1111/cobi.12796

Brockington, D. (2002). Fortress Conservation: The Preservation of the Mkomazi Game Reserve, Tanzania. Oxford: James Currey.

Burg, V. (2007). Climate change affecting the Okavango Delta (Thesis). Institute of Environmental Engineering. Swiss Federal Institute of Technology, Zurich, Switzerland.

Ceausu, S., Graves, R. A., Killion, A. K., Svenning, J., and Carter, N. H. (2020). Governing tradeoffs in ecosystem services and disservices to achieve humanwildlife coexistence. Conserv. Biol. 33, 543-553. doi: 10.1111/cobi.13241

Challender, D., Harrop, S., and MacMillan, D. (2015). Towards informed and multi-faceted wildlife trade interventions. Glob. Ecol. Conserv. 3, 129-148. doi: 10.1016/j.gecco.2014.11.010

Challender, D. W. S., and MacMillan, D. C. (2014). Poaching is more than an enforcement problem. Conserv. Lett. 7, 484-494. doi: 10.1111/conl.12082

Chan, K. M. A., Boyd, D. R., Gould, R. K., Jetzkowitz, J., Liu, J., Muraca, B., et. al. (2020). Levers and leverage points for pathways to sustainability. People Nat. 2, 693-717. doi: 10.1002/pan3.10124

Chase, M. (2011). Dry Season Fixed-Wing Aerial Survey of Elephants and Wildlife in Northern Botswana, October-November 2010. Botswana: Department of Wildlife and National Parks.

Chatty, D., and Colchester, M. (2002). Conservation and Mobile Indigenous Peoples: Displacement, Forced Settlement, and Sustainable Development. New York, NY: Berghahn Books.

Conservation Measures Partnership (CMP) (2007). Open Standards for the Practice of Conservation. Version 2.0. Available online at: https://www.cbd.int/doc/pa/ tools/Open $\% 20$ standards $\% 20$ for $\% 20$ the $\% 20$ practice $\% 20$ of $\% 20$ conservation. pdf (accessed January 15, 2021).

Conservation South Africa (CSA) (2019). Annual Report 2018-2019. Conservation South Africa.

Conservation Stewards Program (CSP) (2021). Stewardship Guidelines-CSP. Available online at: https://www.conservation.org/about/conservationstewards-program (accessed May 28, 2021).

Cooney, R., Roe, D., Dublin, H., and Booker, F. (2018). Wild life, Wild Livelihoods: Involving Communities in Sustainable Wildlife Management and Combatting the Illegal Wildlife Trade. Nairobi: United Nations Environment Programme.

Cooney, R., Roe, D., Dublin, H., Phelps, J., Wilkie, D., Keane, A., et al. (2016). From poachers to protectors: engaging local communities in solutions to illegal wildlife trade. Conserv. Lett. 10, 367-374. doi: 10.1111/conl.12294
Cumming, D. H. M. (2011). Constraints to Conservation and Development Success at the Wildlife- Livestock-Human Interface in Southern African Transfrontier Conservation Areas: A Preliminary Review. Technical Report to the Wildife Conservation Society's AHEAD Program. Available online at: www.wcs-ahead.org/workinggrps_kaza.html (accessed August 19, 2021).

Cumming, D. H. M., Andersson, J. A., de Garine-Wichatitsky, M., Dzingirai, V., and Giller, K. E. (2013). "Whither TFCAs and people on the edge in Southern Africa?" in Transfrontier Conservation Areas: People Living on the Edge, eds J. A. Andersson, M. de Garine-Wichatitsky, D. H. M. Cumming, V. Dzingirai, and K. E.Giller (Abingdon, Oxon: Routledge), 192.

Cumming, G. S., Cumming, D. H. M., and Redman, C. L. (2006). Scale mismatches in social-ecological systems: causes, consequences, and solutions. Ecol. Soci. 11:14. doi: 10.5751/ES-01569-110114

Darkoh, M. B. K., and Mbaiwa, J. E. (2009). Land-use and resource conflicts in the Okavango Delta, Botswana. Afr. J. Ecol. 47, 161-165. doi: 10.1111/j.1365-2028.2008.01064.x

De Garine-Wichatitsky, M., Miguel, E., Mukamuri, B., Garine-Wichatitsky, E., Wencelius, J., Pfukenyi, D. M., et al. (2013). Coexisting with wildlife in transfrontier conservation areas in Zimbabwe: cattle owners' awareness of disease risks and perceptions of the role played by wildlife. Comp. Immunol. Microbiol. Infect. Dis. 36, 321-332. doi: 10.1016/j.cimid.2012.10.007

Deutsche Gesellschaft für Internationale Zusammenarbeit (GIZ) (2019). Herding 4 Health Report. Deutsche Gesellschaft für Internationale Zusammenarbeit.

Dickman, A. J. (2010). Complexities of conflict: the importance of considering social factors for effectively resolving human-wildlife conflict. Anim. Conserv. 13, 458-466. doi: 10.1111/j.1469-1795.2010.00368.x

Dickson, B. (2008). CITES and the livelihoods of the poor. Oryx 42, 548-553. doi: $10.1017 /$ S0030605307000786

Du Toit, J. T., Rogers, K. H., and Biggs, H.C. (eds.). (2003). The Kruger Experience: Ecology and Management of Savanna Heterogeneity. Washington, DC: Island Press.

Duffy, R., Massé, F., Smidt, E., Marijnen, E., Büscher, B., Verweijen, J., et al. (2019). Why we must question the militarization of conservation. Biol. Conserv. 232, 66-73. doi: 10.1016/j.biocon.2019.01.013

Duffy, R., and St. John, F. A. V. (2013). Poverty, Poaching, and Trafficking: What are the Links? London: Evidence on Demand.

Ferguson, K., and Hanks, J. (eds.). (2010). Fencing Impacts: A Review of the Environmental, Social and Economic Impacts of Game and Veterinary Fencing in Africa With Particular Reference to the Great Limpopo and KavangoZambezi Transfrontier Conservation Areas. Pretoria: Mammal Research Institute.

Frank, B., and Glikman, J. (2019). "Human-wildlife conflicts and the need to include coexistence," in Human-Wildlife Interactions: Turning Conflict into Coexistence, eds B. Frank, J. Glikman, and S. Marchini (Cambridge: Cambridge University Press), 1-19.

Frost, P. G. H., and Bond, I. (2008). The CAMPFIRE programme in Zimbabwe: payments for wildlife services. Ecol. Econo. 65, 776-787. doi: 10.1016/j.ecolecon.2007.09.018

Fynn, R., and Kolawole, O. (2020). Poaching and the Problem With Conservation in Africa (commentary). Mongabay Online. Available online at: https://news. mongabay.com/2020/03/poaching-and-the-problem-with-conservation-inafrica-commentary/ (accessed August 19, 2021).

Fynn, R. W. S., Augustine, D. J., Peel, M. J. S., and de Garine-Wichatitsky,. M. (2016). Strategic management of livestock to improve biodiversity conservation in African Savannahs: a conceptual basis for wildlife-livestock co-existence. J. Appl. Ecol. 53, 388-397. doi: 10.1111/1365-2664.12591

Gaborone Declaration for Sustainability in Africa (GDSA) (2018). Case Study: Herding for Health. Available online at: http://www.gaboronedeclaration.com/ case-studies-from-the-gdsa/case-study-herding-for-health-2018 (accessed March 15, 2020).

Gómez, A., and Aguirre, A. A. (2008). Infectious diseases and the illegal wildlife trade. Ann. N. Y. Acad. Sci. 114, 16-19. doi: 10.1196/annals,.14 28.046

Habu Elephant Development Trust (HEDT) (2019). HEDT Progress Report to FAO. Habu Elephant Development Trust.

Herding for Health (H4H) (2019). Climate Vulnerability Assessment. Unpublished Report. Herding for Health. 
Kavango Zambezi Transfrontier Area (KAZA) (2014). Master Integrated Development Plan. 2015-2020. KfW Federal Ministry for Cooperation and Dev. Available online at: https://library.wur.nl/ojs/index.php/Botswana_documents/ article/view/16016 (accessed August 19, 2021).

Keane, A., Jones, J. P. G., Edwards-Jones, G., and Milner-Gulland, E. J. (2008). The sleeping policeman: understanding issues of enforcement and compliance in conservation. Anim. Conserv. 11, 75-82. doi: 10.1111/j.1469-1795.2008.0 0170.x

Keesing, F., Ostfeld, R. S., Okanga, S., Huckett, S., Bayles, B. R., Chaplin-Kramer, R., et al. (2018). Consequences of integrating livestock and wildlife in an African savanna. Nat. Sustain. 1, 566-573. doi: 10.1038/s41893-018-0149-2

Kiffner, C., Kioko, J., Baylis, J., Beckwith, C., Brunner, C., Burns, C., et al. (2020). Long-term persistence of wildlife populations in a pastoral area. Ecol. Evol. 10, 10000-10016. doi: 10.1002/ece3.6658

Knox, J., Ruppert, K., Frank, B., Sponarski, C. C., and Glikman, J. A. (2021). Usage, definition, and measurement of coexistence, tolerance and acceptance in wildlife conservation research in Africa. Ambio 50, 2, 301-313. doi: 10.1007/s13280-020-01352-6

Kock, R. A., Kock, M., Cleaveland, S., and Thomson, G. (2009). "Health and disease in wild rangelands," in Wild Rangelands: Conserving Wildlife While Maintaining Livestock in Semi-Arid Ecosystems, eds J. T. Du Toit, R. A. Kock, and J. C. Deutsch (Chichester: John Wiley and Sons), 98-128.

Kremen, C., and Merenlender, A. M. (2018). Landscapes that work for biodiversity and people. Science 362:eaau6020. doi: 10.1126/science.aau6020

LeFlore, E., Fuller, T., Tomeletso, M., and Stein, A. (2019). Livestock depredation by large carnivores in northern Botswana. Glob. Ecol. Conserv. 18:e00592. doi: 10.1016/j.gecco.2019.e00592

Lewis, D. (1990). Wildlife conservation outside protected areaslessons from an experiment in Zambia. Conserv. Biol. 4, 171-180. doi: 10.1111/j.1523-1739.1990.tb00106.x

Lindsey, P., Allan, J., Brehony, P., Dickman, A., Robson, A., Begg, C., et al. (2020). Conserving Africa's wildlife and wildlands through COVID-19 crisis and beyond. Nat. Ecol. Evol. 4, 1300-1310. doi: 10.1038/s41559-020-1275-6

Lindsey, P., Balme, G., Becker, M., Begg, C., Bento, C., Bocchino, C., et al. (2013). The bushmeat trade in African savannas: impacts, drivers, and possible solutions. Biol. Conserv. 160, 80-96. doi: 10.1016/j.biocon.2012.12.020

Livingstone, D. M. (1857). Missionary Travels in South Africa. Vol. 2. Santa Barbara, CA: The Narrative Press.

Lotter, W., and Clark, K. (2014). Community involvement and joint operations aid effective anti-poaching in Tanzania. Parks 20, 19-28.

Magole, L. I., and Magole, L. (2009). The Okavango: whose delta is it? Phys. Chem. Earth 34, 874-880. doi: 10.1016/j.pce.2009.07.011

Massé, F. (2016). The political ecology of human-wildlife conflict: producing wilderness, insecurity, and displacement in the Limpopo National Park. Conserv. Soc. 14, 100-111. doi: 10.4103/0972-4923.186331

Massé, F., Gardiner, A., Lubilo, R., and Themba, M. (2017). Inclusive anti-poaching? exploring the potential and challenges of community-based anti-poaching. South Afr. Crime Q. 60, 19-27. doi: 10.17159/2413-3108/2017/v0n60a1732

Meat Naturally (2019). MN Auction Sales Report South Africa. Unpublished Data. South Africa, Matatiele: Meat Naturally PTY.

Miller, J. R., Morton, L. W., Engle, D. M., Debinski, D. M., and Harr, R. N. (2012). Nature reserves as catalysts for landscape chane. Front. Ecol. Environ. 10, 144-152. doi: $10.1890 / 100227$

Mora, C., and Sale, P. F. (2011). Ongoing global biodiversity loss and the need to move beyond protected areas: a review of the technical and practical shortcomings of protected areas on land and sea. Mar. Ecol. Prog. Ser. 434, 251-266. doi: 10.3354/meps09214

Muntifering, J. (2019). "Engaging and Empowering Local People in Saving Rhinos-a case from Kunene, Namibia," in Etosha 112 Years and Counting Symposium (Organised by Etosha Ecological Institute, Mokuti Lodge, Etosha National Park: Namibia).

Mupatsi, N. M. (2020). Observed and Potential Environmental Impacts of Covid19 in Africa. Harare: Department of Soil Science and Agricultural Engineering, Faculty of Agriculture, University of Zimbabwe.

Murphree, M. (2004). Communal approaches to natural resource management in Africa: from whence to where? J. Int. Wildl. Law Policy 7, 203-216. doi: $10.1080 / 13880290490883250$
Murphree, M. W. (2009). The strategic pillars of communal natural resource management: benefit, empowerment, and conservation. Biodivers. Conserv. 18, 2551-2562. doi: 10.1007/s10531-009-9644-0

Musoke, J., Hlokwe, T., Marcotty, T., du Plessis, B. J. A., and Michel, A. L. (2015). Spillover of mycobacterium bovis from wildlife to livestock, South Africa. Emerging Infect. Dis. 21:448. doi: 10.3201/eid2103.131690

Niesten, E., Zurita, P., and Banks, S. (2010). Conservation agreements as a tool to generate direct incentives for biodiversity conservation. Biodiversity 11, 5-8. doi: $10.1080 / 14888386.2010 .9712639$

Northern Rangelands Trust (2019). State of Conservancies Report. Centurionsafaris. Available online at: https://staticl.squarespace.com/static/ 5af1629f12b13f5ce97ca0b5/t/5e398ee62156d43c562498bf/1580830499016/ LOWRES.FINAL_State+of+Conservancies+Report+2019.pdf_ (accessed August 19, 2021).

Nyhus, P. (2016). Human-wildlife conflict and coexistence. Annu. Rev. Environ. Resour. 41, 143-171. doi: 10.1146/annurev-environ-110615-085634

Odadi, W. O., Fargione, J., and Rubenstein, D. I. (2017). Vegetation, wildlife, and livestock responses to planned grazing management in an African pastoral landscape. Land Degrad. Dev. 28, 2030-2038. doi: 10.1002/ldr.2725

Ogada, M. O. (2001). Relationships between Livestock Husbandry Methods and Depredation by Large Carnivore in Laikipia District, Kenya (M.Sc. thesis). Kenyatta University, Nairobi, Kenya.

One Health Initiative (OHI) (2021). Available at: www.onehealthinitiative.com (accessed Feburary 20, 2021).

Ostrom, E. (2007). A diagnostic approach for going beyond panaceas. Proc. Natl. Acad. Sci. U.S.A. 104, 15181-15187. doi: 10.1073/pnas.0702288104

Ostrom, E. (2009). A general framework for analysing sustainability of socioecological systems. Science 325, 419-422. doi: 10.1126/science.1172133

Ostrom, E., and Nagendra, H. (2006). Insights on linking forests, trees, and people from the air, on the ground, and in the laboratory. Proc. Natl. Acad. Sci. U.S.A. 103, 19224-19231. doi: 10.1073/pnas.0607962103

Painter, M., and Wilkie, D. S. (2015). Rewards and Risks Associated With Community Engagement in Anti-Poaching and Anti-Trafficking. Biodiversity Technical Brief. Washington, DC: U.S. Agency for International Development.

Peace Parks Foundation (PPF) (2018). Herding 4 Health. Available online at: https://www.peaceparks.org/h4h/ (accessed January 15, 2021).

Persha, L., Agrawal, A., and Chhatre, A. (2011). Social and ecological synergy: local rule making, forest livelihoods, and biodiversity conservation. Science 331, 1606-1608. doi: 10.1126/science.1199343

Phelps, J., Biggs, D., and Webb, E. L. (2016). Tools and terms for understanding illegal wildlife trade. Front. Ecol. Environ. 14, 479-489. doi: 10.1002/fee.1325

Richardson, H. (2021). A Big Oil Project in Africa Threatens Okavango Region. Yale Environment360. New Haven, CT: Yale School of the Environment.

Roe, D., and Booker, F. (2019). Engaging local communities in tackling illegal wildlife trade: a synthesis of approaches and lessons for best practice. Conserv. Sci. Pract. 1:e26. doi: 10.1111/csp2.26

Roe, D., Cooney, R., Dublin, H. T., Challender, D. W., Biggs, D., Skinner, D., et al. (2015). Beyond Enforcement: Engaging Communities in Tackling Wildlife Crime. London: International Institute for Environment and Development.

Rogan, M. S., Lindsey, P. A., and McNutt, J. W. (2015). Illegal Bushmeat Hunting in the Okavango Delta, Botswana: Drivers, Impacts, and Potential Solutions. Harare: Food and Agriculture Organization of the United Nations.

Rogan, M. S., Lindsey, P. A., Tambling, C. J., Golabek, K. A., Chase, M. J., Collins, K., et al. (2017). Illegal bushmeat hunters compete with predators and threaten wild herbivore populations in a global tourism hotspot. Biol. Conserv. 210, 233-242. doi: 10.1016/j.biocon.2017.04.020

Rogan, M. S., Miller, J. R. B., Lindsey, P. A., and McNutt, J. W. (2018). Socioeconomic drivers of illegal bushmeat hunting in a Southern African Savanna. Biol. Conserv. 226, 24-31. doi: 10.1016/j.biocon,.2018.07.019

Scott, J. C. (1989). Everyday forms of resistance. Copenhagen J. Asian Stud. 4, 33-33. doi: 10.22439 /cjas.v4i1.1765

Skinner, D., Dublin, H., Niskanen, L., Roe, D., and Vishwanath, A. (2018). Local Communities: First Line of Defence Against Illegal Wildlife Trade (FLoD). Guidance for Implementing the FLoD Methodology. London and Gland: IIED and IUCN.

Smith, R. D., and Maltby, E. (2003). Using and Ecosystem Approach to Implement the CBD. A Global Synthesis Report Drawing Lessons From Three Regional Pathfinder Workshops. An Ecosystem Approach to CBD: From Concept to 
Action. A Case Study. Available online at: https://www.cbd.int/doc/meetings/ esa/ecosys-01/information/ecosys-01-inf-02-en.pdf (accessed August 19, 2021).

Southern Africa Wildlife College (SAWC) (2021). Herding 4 Health. Available online at: https://wildlifecollege.org.za/herding-for-health/ (accessed January 15, 2021).

Thakadu, O. (2005). Success factors in community based natural resources management in northern Botswana: lessons from practice. Nat. Resour. Forum 29, 119-212. doi: 10.1111/j.1477-8947.2005.00130.x

Thomson, G., and Penrith, M. L. (2011). Animal Health Policy, Legislation and Trade in Beef in the Five Participating States of the Kavango Zambezi Transfrontier Conservation Area (KAZA TFCA). Technical Report to the Wildlife Conservation Society's AHEAD Program. Available online at: http://www.wcsahead.org/workinggrps_kaza.html (accessed August 19, 2021).

Thomson, G. R., Penrith, M.-L., Atkinson, M. W., Thalwitzer, S., Mancuso, A., Atkinson, S. J., et al. (2013). International trade standards for commodities and products derived from animals: The need for a system that integrates food safety and animal disease risk management. Transbound. Emerg. Dis. 60, 507-515.

Tyrell, P., Russell, S., and Western, D. (2017). Seasonal movements of wildlife and livestock in a heterogenous pastoral landscape: implications for coexistence and community based conservation. Glob. Ecol. Conserv. 12, 59-72. doi: 10.1016/j.gecco.2017.08.006

United Nations Office on Drugs and Crime (UNODC) (2020). World Wildlife Crime Report. United Nations Office on Drugs and Crime.

University of Pretoria (UP) (2021). Herding for Health. Available online at: https://www.up.ac.za/research-matters/news/post_2561144-herding-forhealth (accessed February 08, 2021).

Valters, C. (2014). Theories of Change in International Development: Communication, Learning or Accountability. London: The Justice and Security Research Programme.

Van Rooyen, J. (2017). Livestock production and animal health management systems in communal farming areas at the wildife-livestock interface in Southern Africa [PhD dissertation]. Faculty of Veterinary Science, University of Pretoria, Pretoria, South Africa.

Vogel, I. (2012). Review of the Use of Theory of Change in International Development. London: Department for International Development.

Weise, F. J., Hayward, M. W., Aguirre, R. C., Tomeletso, M., Gadimang, P., Somers, M. J., et al. (2018). Size, shape and maintenance matter: a critical appraisal of a global carnivore conflict mitigation strategy- livestock protection kraals in northern Botswana. Biol. Conserv. 225, 88-97. doi: 10.1016/j.biocon.2018.06.023

West, P., Igoe, J., and Brockington, D. (2006). Parks and peoples: the social impact of protected areas. Annu. Rev. Anthropol. 35, 251-277. doi: 10.1146/annurev.anthro.35.081705.123308

Western, D., Tyrell, P., Brehony, P., Russell, S., Western, G., and Kamanga, J. (2020). Conservation from the inside-out. Winning space and a place for wildlife in working landscapes. People Nat. 2, 279-291. doi: 10.1002/pan3.10077

Western, D., Nightingale, D., Mose, V., Sipitiek, J., and Kimiti, K. (2019). Variability and change in maasai views of wildlife and the implications for conservation. Hum. Ecol. 47, 205-216. doi: 10.1007/s10745-019-0065-8

Wittemyer, G., Northrup, J. M., Blanc, J., Douglas-Hamilton, I., Omondi, P., and Burnham, K. P. (2014). Illegal killing for ivory drives global decline in African elephants. PNAS 11, 13117-13121. doi: 10.1073/pnas.1403984111

Woodroffe, R., Thirgood, S., and Rabinowitz, A. (2005). "The future of coexistence: resolving human-wildlife conflicts in a changing world," in People and Wildlife: Conflict or Coexistence? ed R. Woodroffe (Cambridge: Cambridge University Press), 388-405.

Zinsstag, J., Schelling, E., Waltner-Toews, D., and Tanner, M. (2011). From “one medicine" to "one health" and systemic approaches to health and well being. Prev. Vet. Med. 101, 148-156. doi: 10.1016/j.prevetmed.2010.07.003

Conflict of Interest: The authors declare that the research was conducted in the absence of any commercial or financial relationships that could be construed as a potential conflict of interest.

Publisher's Note: All claims expressed in this article are solely those of the authors and do not necessarily represent those of their affiliated organizations, or those of the publisher, the editors and the reviewers. Any product that may be evaluated in this article, or claim that may be made by its manufacturer, is not guaranteed or endorsed by the publisher.

Copyright (C) 2021 Heermans, van Rooyen, Fynn, Biggs, Lewis and McNutt. This is an open-access article distributed under the terms of the Creative Commons Attribution License (CC BY). The use, distribution or reproduction in other forums is permitted, provided the original author(s) and the copyright owner(s) are credited and that the original publication in this journal is cited, in accordance with accepted academic practice. No use, distribution or reproduction is permitted which does not comply with these terms. 